Logic \& Logical Philosophy

Volume 1 (1993), 3-6

\title{
Aim, the Scope and Editorial Policy of the Journal
}

1. Logic, philosophy and science are among the most distinguished achievements of Western civilization. Their occurrence in ancient Greece and further development through the millennia, including long-time cooperation, is indeed the most important legacy of the Greek rationalism.

However, at the present time quite a lot of people, trying to be more modern $^{1}$ than is reasonable to be, claim $^{2}$ that this reverend tradition is over.

2. We disagree. But we see that something very basic is menaced.

On the one hand, many people lost faith and patience which, from a pragmatic point of view, is necessary for searching, discovering and understanding. The remedy for this weakness is to be patient, faithful and curious, and, of course, critical.

On the other hand, the close bond connecting philosophy, in particular metaphysics, with science seems indeed to be broken. It was partly caused by scientists, who under the influence of narrow-minded positivism lost philosophical curiosity and motivation; partly by philosophers because of their growing ignorance in sciences, usual for laymen, and lost of heart for real philosophical problems.

The only reasonable remedy here is to bring back the problems of real philosophy ${ }^{3}$ and to act in philosophy as in science, in particular like in mathematics and logic.

\footnotetext{
${ }^{1}$ I.e., postmodern.

${ }^{2}$ Some of them claim even that science is magic, philosophy is dead, logic is illogical and similar jokes.

${ }^{3}$ I.e., first of all, questions concerning the world, its nature, mechanism and origin, as well as similar questions concerning human beings.
} 
3. It, inter alia, means: take an interesting philosophical problem(s) and try to answer it (them) theoretically, i.e., by means of a theory.

To this end, we must start with a conceptual analysis, first determining relevant primitive concepts; next clarify them through informal (conceptual or phenomenological) discussion to find reasonable axioms, which finally are subject to logical deduction. The method is sound if some theorems answer, or at least illuminate, the starting problem.

Logical philosophy is philosophy done in this way, i.e., philosophy produced by answering philosophical questions by means of logical methods and procedures.

4. The above program is exactly the program of Leibniz, revived at the beginning of the century by B. Russell in his idea and practice of mathematical philosophy.

Russell's program is, undoubtedly, one of the leading ideas of contemporary philosophy. In particular it is quite important for Anglo-American analytical tradition, where it has occurred several times under several names, including Russellian mathematical philosophy, formal philosophy, exact philosophy, strict philosophy, somewhat misleading and ambiguous scientific philosophy.

5. Under the immediate influence of B. Russell, who with F. Brentano is one of two great grandfathers of Polish analytical philosophy, the program also became crucial for Polish logic and philosophy.

As a matter of fact, the program of logical philosophy, i.e. the program of axiomatization of philosophy by means of logic, was stated explicitly by Jan Łukasiewicz in his 1927 lecture "Toward a method in philosophy" read at the Second Polish Philosophical Convention. ${ }^{4}$

It was also successfully exercised by Jan Łukasiewicz himself, Stanisław Leśniewski, Kazimierz Ajdukiewicz, Alfred Tarski, Stanisław Jaśkowski and Roman Suszko, to mention only a few. As the emergence of the present journal made clear, the program is still one of the basic ingredients of logic and philosophy here.

6. Now, with seventy down, the situation of logic and philosophy is a bit different.

First of all, logic itself is different. At the end of the century logic is not a discipline but rather a family or a bundle of disciplines. Its kernel is

\footnotetext{
${ }^{4}$ Cf. J. Łukasiewicz "O metodę w filozofii", Księga Pamiątkowa II Polskiego Zjazdu Filozoficznego, Warszawa 1927. Przeglad Filozoficzny, 31 (1928), 3-5.
} 
the same as before. It is a theory of a complex and rich domain of logical calculi. More specialized and particular parts of logic are built up on its borders with connected disciplines.

7. The main change is that, presently, logic $(\mathbf{L})$ is much more interdisciplinary than during time of Russell and Łukasiewicz. It is still closely connected with philosophy $(\mathbf{P})$ and mathematics $(\mathbf{M})$. But now logic is, in addition, closely connected with linguistics $(\mathbf{L N})$, cognitive sciences $(\mathbf{C})$, informatics (I) and computer science (CS). The latter three did not exist seventy years ago.

Specifications of interdisciplinary oriented logic result in special branches of modern logic: mathematical logic (ML), which is a part of logic for application in mathematics ${ }^{5}$; philosophical logic $(\mathbf{P L})$, i.e. a part of logic which can be used in philosophy. In addition, in the last fifteen years we see the emergence of linguistic logic (LL), cognitive logic (CL), informatics logic (IL) and computer science logic (CSL) which, step by step, are reaching maturity.

8. To sum up, the present situation of logic can be pictured as follows:

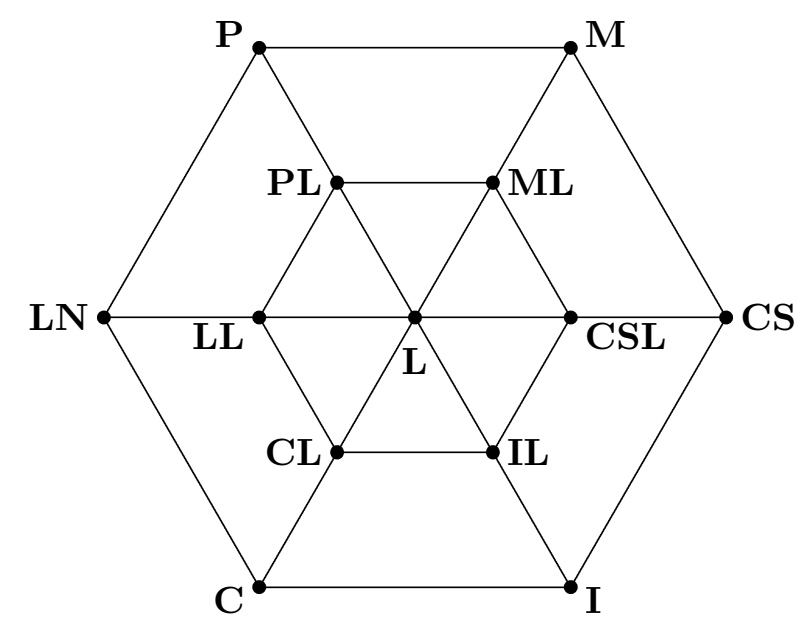

\footnotetext{
${ }^{5}$ Notice the remarkable change of the name's meaning: previously "mathematical logic" meant "symbolic or formal logic", whereas the present ML used to be named "foundations of mathematics".
} 
The internal hexagon diagram the domain of logic with its kernel $\mathbf{L}$; six branches, i.e. PL, ML, CSL, IL, CL, LL; and six interdisciplinary axes; whereas the full hexagon presents the network of the seven connected disciplines.

9. The aim of this journal is to promote interdisciplinary research in domains outlined above, particularly in philosophical logic and logical philosophy.

The editors especially welcome logical papers devoted to discussion of philosophical problems or problems in relevant disciplines pointed above.

10. Logic and Logical Philosophy is a twin journal to Reports on Mathematical Logic.

Both journals share the same editorial policy, the standard of publication and the task. RML, which are chiefly devoted to logical calculi, are in principle more mathematically oriented, whereas LLP is more philosophical ${ }^{6}$.

The Editors

\footnotetext{
${ }^{6}$ In spirit, but not in techniques.
} 